\title{
氢键促进的级联重排
}

\author{
王亚俐 ${ }^{a} \quad$ 郭红超* ${ }^{*}$ \\ $\left({ }^{a}\right.$ 榆林学院化学与化工学院 陕西榆林 71900) \\ $\left({ }^{b}\right.$ 中国农业大学化学系 北京 100193)
}

\section{Hydrogen-Bonding-Promoted Cascade Rearrangement}

\author{
Wang, Yali ${ }^{a}$ Guo, Hongchao ${ }^{*}, b$ \\ ( ${ }^{a}$ School of Chemistry \& Chemical Engineering, Yulin University, Yulin, Shaanxi 719000) \\ ( ${ }^{b}$ Department of Chemistry, China Agricultural University, Beijing 100193)
}

多环喹啉衍生物是一类非常重要的化合物, 广泛存 在于天然产物与生物活性分子中, 在过去几十年中受到 广泛关注. 从易得原料快速构建多环喹啉衍生物, 开发 简单、高效、步骤经济性的合成方法具有重要意义.

级联反应是开展天然产物全合成和合成砌块构建 的重要方法 ${ }^{[1]}$, 其中基于异腈的级联反应为杂环化合物 的制备提供了非常有用的途径 ${ }^{[2]}$. 色胺衍生的异腈, 也 就是在吲哚的 3-位碳上安装了一个链状异腈的吲哚化 合物, 在串联反应中展示了极为高效的反应特性, 作为 初始原料已经被用于若干串联反应来构建螺环吲哚啉 化合物, 相关级联反应研究取得了极大的成功 ${ }^{[3-7]}$. 然 而, 基于色胺衍生异腈的反应模式和反应产物的多样性 仍然比较有限, 因此围绕 3-(2-异氧乙基)吲哚开发更多 的新反应仍然是一个挑战性的科学问题和迫切需要开 展的工作.

在这种背景下, 基于异腈与 1,3-偶极子可以相互作 用 $^{[8]}$, 近日, 苏州大学材料与化学化工学部纪顺俊、徐小 平等与郑州大学化学学院蓝宇等一起探索了偶氮甲亚 胺叶立德与 3-(2-异氧乙基)吲哚之间的反应, 所分离得 到的产物并非预期将生成的生成螺环吲哚啉化合物, 而 是一种多环吡咯并 [2,3-c]喹啉衍生物(图 1), 由此成功开 发了一种不用催化剂的 3-(2-异氰乙基)吲哚与偶氮甲亚 胺叶立德之间的级联重排反应 ${ }^{[9]}$.

特别需要指出的是, 该反应仅需要在甲醇的辅助下 便可在室温顺利进行, 以中等到良好产率得到多环吡咯 并[2,3-c]喹啉类衍生物. 这项工作是一个独特的级联反 应的例子, 反应涉及四个新杂环的形成、吲哚环的开环 以及偶氮甲亚胺叶立德的扩环. 这一新的发现不仅提供
了一个从容易获得的起始材料转化为多环喹啉衍生物 的一步反应方案, 而且该反应独特的反应机理为相关新 反应的设计带来了深刻的启示.

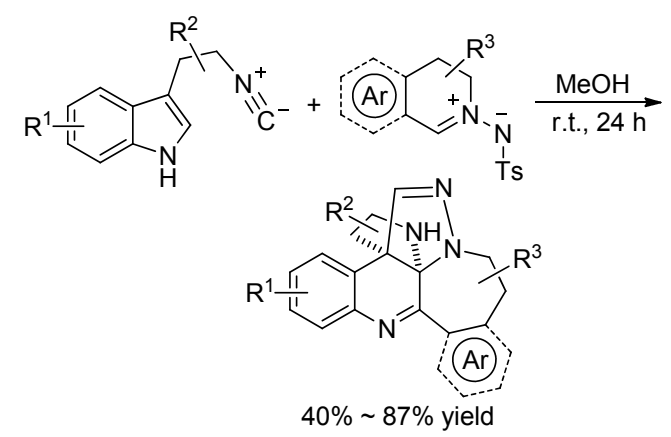

图 1 3-(2-异奢乙基)吲哚与偶氮甲亚胺叶立德的级联重排反 应

Figure 1 Cascade rearrangement reaction of 3-(2-isocyanoethyl) indoles with azomethine imines

作者采用实验和理论计算对该反应的独特机理开 展了深入全面的研究. 作者通过对反应溶剂进行系统考 察后发现，使用醇类溶剂是成功获得最终产物的关键， 当使用其它溶剂时则生成稠合的二氮杂环丁烷化合物, 这表明氢键促进了级联重排过程. 此外, 作者分离得到 了稠合的二氮杂环丁烷和螺环吲哚啉两种反应中间体.

为了进一步揭示该反应的机理，作者进行了密度泛 函理论(DFT)计算, 发现甲醇溶剂通过氢键降低过渡态 的自由能垒. 在对甲苯磺酰基消除步骤中, 它可以与对 甲苯磺酰基结合, 通过氢键过渡态降低级联反应中对甲 苯磺酰基消除和质子转移过程中的自由能垒, 促进对甲 苯磺酰基的离去. 甲醇分子也充当了质子穿梭试剂, 在

* Corresponding author. E-mail: hchguo@cau.edu.cn. Published online January 4, 2021. 
最终产物的生成过程中, 促进后续的质子转移.

基于实验和理论计算结果，作者为该氢键促进的级 联重排反应提出了一个合理的反应机理(图 2). 从这个 机理图可以很容易看出, 甲醇在活化反应物及促进反应 进程中起到了关键作用.

综上所述, 纪顺俊、徐小平、蓝宇等实现了一例独 特的甲醇促进的级联重排反应, 在无催化剂和温和的反
应条件下，3-(2-异氰乙基)吲哚与偶氮甲亚胺叶立德在 甲醇中顺利反应，以中等到良好的产率得到多环吡咯并 [2,3-c] 喹啉类化合物. 实验研究和 DFT 计算表明, 溶剂 甲醇可以通过氢键过渡态降低级联反应中的自由能垒, 并充当了质子穿梭试剂, 促进反应顺利进行. 这一工作 拓宽了色胺衍生的异氰在串联反应中的应用范围，为设 计新反应带来了深刻的启示.<smiles>CC(C)C(C)C</smiles>

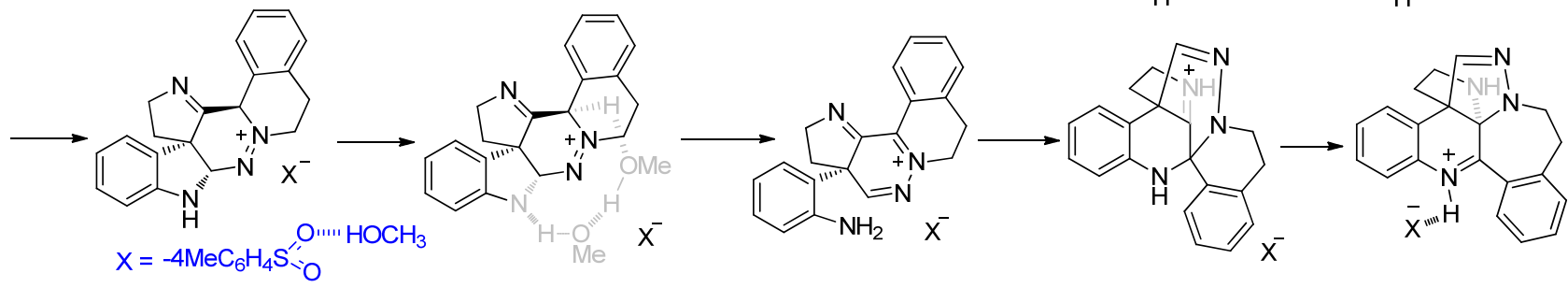

图 2 合理的反应机理

Figure 2 Plausible reaction mechanism

\section{References}

[1] Touré, B. B.; Hall, D. G. Chem. Rev. 2009, 109, 4439.

[2] Wang, W.; Herdtweck, E.; Dömling, A. Chem. Commun. 2010, 46, 770 .

[3] Wang, X.; Wang, S.-Y.; Ji, S.-J. Org. Lett. 2013, 15, 1954.

[4] Zhao, X.-H.; Liu, X.-H.; Mei, H.-J.; Guo, J.; Lin, L.-L.; Feng, X.-M. Angew. Chem., Int. Ed. 2015, 54, 4032.

[5] Saya, J. M.; Roose, T. R.; Peek, J. J.; Weijers, B.; de Waal, T. J. S.;
Vande Velde, C. M. L.; Orru, R. V. A.; Ruijter, E. Angew. Chem., Int. Ed. 2018, 57, 15232.

[6] Li, L.-H.; Liu, J.-X.; Shi, M. Org. Lett. 2018, 20, 7076.

[7] Chen, G.-S.; Chen, S.-J.; Luo, J.; Mao, X.-Y.; Chan, A. S.-C.; Sun, R. W.-Y.; Liu, Y.-L. Angew. Chem., Int. Ed. 2020, 59, 614.

[8] Grassot, J.; Masson, G.; Zhu, J.-P. Angew. Chem., Int. Ed. 2008, 47, 947.

[9] Cao, W.-B.; Li, S.; Xu, M.-M.; Li, H.; Xu, X.-P.; Lan, Y.; Ji, S.-J. Angew. Chem., Int. Ed. 2020, 59, 21425. 